\title{
Thermographic and reflectographic imaging investigations on Baroque paintings preserved at the Chigi Palace in Ariccia
}

\author{
Sofia Ceccarelli ${ }^{1}$, Noemi Orazi ${ }^{1}$, Fulvio Mercuri ${ }^{1}$, Stefano Paoloni ${ }^{1}$, Ugo Zammit ${ }^{1}$, Francesco Petrucci $^{2}$ \\ ${ }^{1}$ Dipartimento di Ingegneria Industriale, Università degli Studi di Roma Tor Vergata, via del Politecnico 1, 00133, Rome, Italy \\ 2 Palazzo Chigi, Piazza di Corte 14, 00040, Ariccia, Italy
}

\begin{abstract}
In this work, two different mid-infrared imaging techniques operating in the 3-5 $\mu \mathrm{m}$ spectral range are applied to the study of three paintings on canvas, dating back to the XVII century, preserved at the Chigi Palace in Ariccia (Italy). A combined approach based on the use of pulsed thermography and mid-infrared reflectography is proposed for the analysis of the 'Primavera' by Filippo Lauri and Mario Nuzzi, the 'Ritratto di Mario Nuzzi che dipinge un vaso di fiori' by Giovanni Maria Morandi and Mario Nuzzi and the 'Ebbrezza di Noè' by Andrea Sacchi. The aim is to show how the integrated use of these techniques enables a depth-resolved investigation of the entire layered structure of the paintings, from the surface up to the canvas support. The complementarity of the presented results allows an evaluation of the conservative status of the support and the detection of graphical and pictorial features hidden beneath the surface layer, such as pentimenti, as these features are important for the historical and artistic characterisation of the artefact.
\end{abstract}

\section{Section: RESEARCH PAPER}

Keywords: Mid-Infrared imaging; thermography; reflectography; hidden features; Baroque paintings; Chigi Palace

Citation: Sofia Ceccarelli, Noemi Orazi, Fulvio Mercuri, Stefano Paoloni, Ugo Zammit, Francesco Petrucci, Thermographic and reflectographic imaging investigations on Baroque paintings preserved at the Chigi Palace in Ariccia, Acta IMEKO, vol. 10, no. 1, article 25, March 2021, identifier: IMEKO-ACTA10 (2021)-01-25

Editor: Ioan Tudosa, University of Sannio, Italy

Received April 28, 2020; In final form February 2, 2021; Published March 2021

Copyright: This is an open-access article distributed under the terms of the Creative Commons Attribution 3.0 License, which permits unrestricted use, distribution, and reproduction in any medium, provided the original author and source are credited.

Corresponding author: Noemi Orazi, noemi.orazi@uniroma2.it

\section{INTRODUCTION}

In the study of painted artefacts, important information can be obtained by displaying features hidden under the surface pictorial layers, such as underdrawings and pentimenti. Since this kind of information is often not accessible to the naked eye, nondestructive techniques for the inner inspection of artworks are needed. For this purpose, optical methods based on the use of infrared (IR) radiation are nowadays considered effective tools for the analysis of subsurface features in cultural heritage $(\mathrm{CH})$ [1], [2] items. Among these methods, infrared reflectography (IRR) is the most commonly adopted technique, primarily employing radiation in the near infrared range. In particular, near-IR reflectography (NIR) provides information about the very first layers beneath the painted layer [3], [4], thus allowing the detection of underdrawings and subsurface elements by means of different types of imaging device [5]-[9]. All these approaches explore the artwork's layered structure through IR images, which record with increasing resolution and, consequently, at increasing cost [10], [11].
The most interesting underlying elements of an artefact with a stratigraphic structure are often beneath multiple layers of painting and materials. In this respect, the use of mid-infrared range $(3-5 \mu \mathrm{m})$ imaging analyses makes it possible to increase the depth range of non-destructive investigations and, thus, to reach integrative and complementary information that would not be achievable using only NIR techniques [12].

In recent years, imaging techniques operating in the midinfrared range have been employed on different kinds of painted artefact, such as wooden/canvas paintings [13] and illuminations [14], by using either pulsed thermography (PT) and/or midinfrared reflectography (MIR).

PT is based on the detection of the time-dependent distribution of IR radiation emitted from the sample surface following heating induced by the absorption of a short light pulse in the visible range (VIS). This technique has proved to be able to characterise the main surface and subsurface elements of $\mathrm{CH}$ artefacts [15]-[17], providing information on both the conservative state and subsurface graphical and pictorial features, such as underdrawings and pentimenti [18]. Similar items have also been investigated using MIR, which collects the images immediately after the beginning of the illumination of the sample 
with mid-infrared radiation, thus allowing a reduction in the number of stray effects on the reflectographic image caused by the mid-infrared radiation emitted from the heating of the sample.

The novel approach proposed in this work is based on the combined use of the two mid-wave infrared imaging techniques, usually carried out by means of a separate setup, to obtain complementary information on the artwork. In this approach, the same IR camera is used to record both the thermograms and reflectograms corresponding to the same area of the painting. By so doing, the comparative analysis of the two recorded images allows a better understating of the features revealed by the adopted techniques, which can be further improved by the combined numerical processing of the images.

In the framework of this ADAMO project [19], the proposed integrated use of PT and MIR has been adopted for the depthresolved investigation of three paintings on canvas, dating from the XVII century and belonging to the Baroque period, in order to detect subsurface features and structural elements.

\section{THE BAROQUE PAINTINGS}

The investigated paintings are preserved at the Chigi Palace in Ariccia (Rome, Italy), which is considered a primary example of Italian Baroque architecture. The palace was originally built for a rich, local family during the second half of the XVI century, and it was restored by Gian Lorenzo Bernini for the Chigi family between 1664 and 1672 [20]. The restoration of the palace was carried out with the aim of exhibiting the splendour and the importance of the Chigi family, one of the leading families in the Italian papal lineage. In this palace, several valuable paintings are preserved, mainly dating back to the XVII century. Among these artworks, three paintings were investigated as part of this study: 'Ritratto di Mario Nuzzi che dipinge un vaso di fiori' by Giovanni Maria Morandi and Mario Nuzzi, 'Primavera' by Filippo Lauri and Mario Nuzzi, and 'Ebbrezza di Noè' by Andrea Sacchi.

\subsection{The portrait}

The 'Ritratto di Mario Nuzzi che dipinge un vaso di fiori' ('Portrait of Mario Nuzzi painting a flower vase') is one of the greatest masterpieces of the Roman Baroque because of its high pictorial quality and the peculiar combination of two pictorial genres (still life and portrait) realised by the two artists. This artwork was painted by Mario Nuzzi and Giovanni Maria

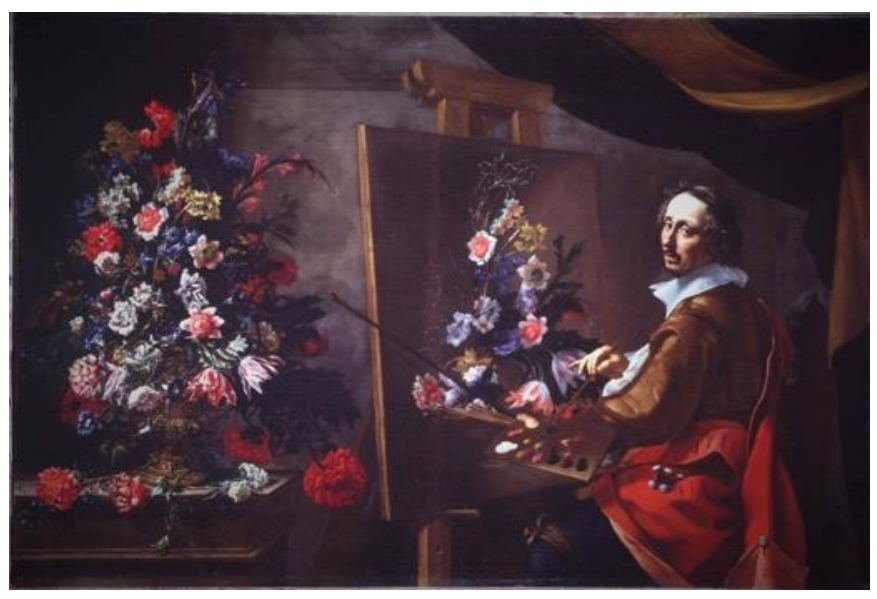

Figure 1. Giovanni Maria Morandi and Mario Nuzzi, 'Ritratto di Mario Nuzzi che dipinge un vaso di fiori', 1658-1659, oil on canvas, $195 \times 265 \mathrm{~cm}$, Chigi Palace, Ariccia.

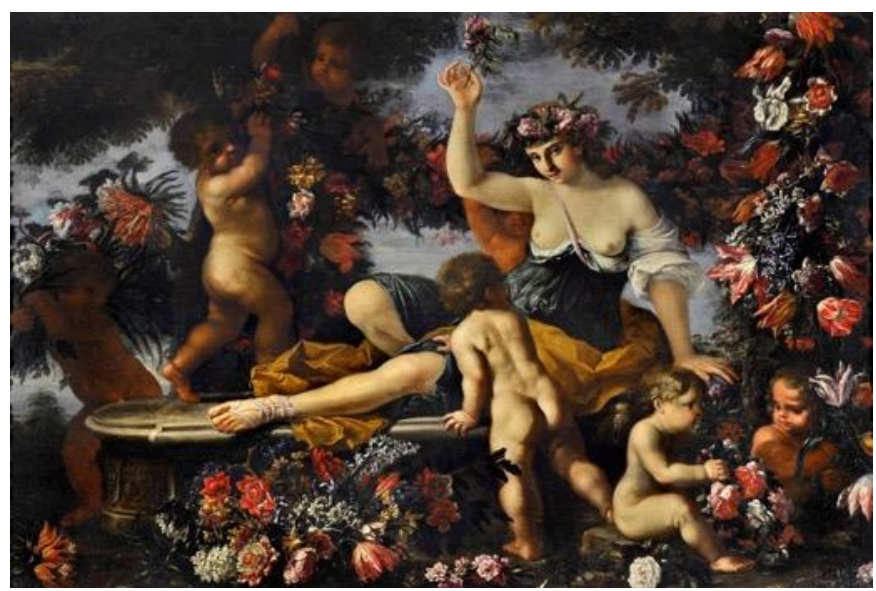

Figure 2. Filippo Lauri and Mario Nuzzi, 'Primavera', 1659, oil on canvas, 150 $\times 250 \mathrm{~cm}$, Chigi Palace, Ariccia.

Morandi, who were responsible for the floral decoration and Nuzzi's portrait, respectively (Figure 1). This painting is a typical example of Baroque portraiture, and the artist, Mario Nuzzi, is represented in his atelier, in front of his easel during the creative process, with a melancholic look towards the viewer. In this painting, Mario Nuzzi, also called Mario de' Fiori for his extraordinary talent for depicting flowers, achieved the highest level of quality in the representation of a single flower vase composition [21], [22]. The canvas is composed of two identical smaller pieces, vertically stitched together. This division was created in order to make it possible for the artists to work separately on the two different parts of the painting [23], [24].

\subsection{The Spring Allegory}

The 'Primavera' ('The Spring') painting was also realised by the collaboration of two artists: Filippo Lauri depicted the female figure and the cherubs, while Mario Nuzzi painted all the garlands and the floral elements (Figure 2).

This artwork belongs to the series 'Le Quattro Stagioni' ('Four Seasons'), nowadays preserved in Ariccia's Chigi Palace and considered one of the greatest examples of Roman Baroque painting. The entire series was commissioned by Flavio Chigi, nephew of Pope Alessandro VII [25], and executed between 1658 and 1659.

The studied painting represents the allegory of spring, symbolising youth, depicted as a beautiful woman surrounded by six cherubs and several types of flower, while holding up a rose as a trophy. In this artwork, the two artists combined their own artistic skills, achieving an incredible harmonisation of the two talents [26]-[28].

\subsection{The Drunkenness of Noah}

The 'Ebbrezza di Noe' ('The Drunkenness of Noah') (Figure 3), preserved at the Chigi Palace, is one of the numerous replicas produced by Andrea Sacchi in the second half of the XVII century. The dating of the painting is uncertain, as is the possibility of establishing whether it is the original version or one of the many replicas [29], [30]. The large number of copies of this painting is due to the following reasons: the importance of this biblical story from Genesis and the painter's constant search for perfection in its artistic production.

The painting represents a famous biblical scene in which Noah is lying on a rock because of his drunkenness and, for this reason, he is being derided by Cam, while the more modest and respectful brothers, Sem and Jafet, look away. This scene was 


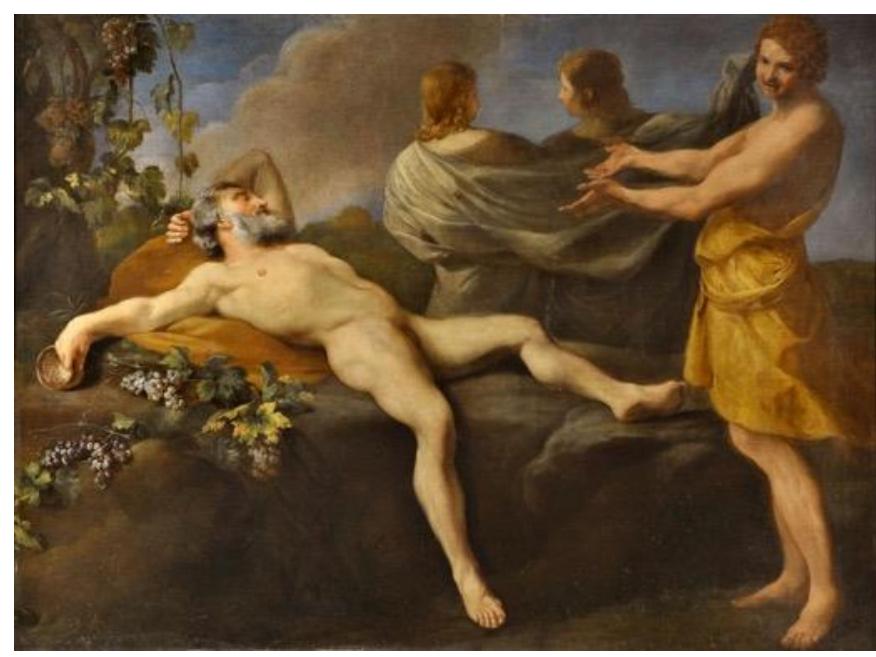

Figure 3. Andrea Sacchi, 'Ebbrezza di Noè', n.a., oil on canvas, $150 \times 205$ cm, Chigi Palace, Ariccia.

represented extensively during the Renaissance period, lasting until the XVII century, referring also to more pagan views, such as those relating to bacchanal models [31].

\section{METHODS}

Among the mid-infrared imaging techniques, PT has become one of the most used methods for the investigation of cultural heritage [1], [32]. It is one of the so-called photothermal techniques, which have been widely used for the determination of the thermal transport properties of several kinds of material [33]-[38]. PT provides a sequence of IR images, referred to as thermograms [39]. The presence of a sub-surface feature leads to local modifications in the amount of emitted IR radiation and, hence, to the formation of contrast in the recorded IR images. In the case of semi-transparent media, such as paintings, the contrast in the thermograms originates in the differences in the local optical properties of the subsurface features compared to those of the surrounding material. More specifically, there are two main opto-thermal mechanisms that enable the buried features to be displayed. The first mechanism occurs when the features are located at a depth in the sample smaller than the penetration depth of the heating VIS light. In this case, the different absorption properties in the visible range of the features with respect to the surroundings may result in a different local temperature increase and, hence, in the contrasted IR emission being recorded in the thermograms. However, when the depth of the subsurface element is too large to be reached by the incident light, the heating of the buried features can only be associated with the diffusion of the heat in the sample depth. Under such circumstances, the contrast is mainly due to the different local values of the IR emissivity.

In the MIR technique, the images are obtained by directing mid-infrared radiation from a suitable source onto the sample. Here, the image contrast originates primarily from the local difference in the reflection of the mid-infrared radiation [40]. For this reason, unlike PT, MIR does not provide information about the depth of the detected features, and its application shows some limitations in the detection of features buried beneath layers that strongly diffuse mid-infrared radiation.

The setup employed for the analysis of the paintings in the Chigi Palace is as follows. In the PT technique, the sample heating is induced by means of two $3 \mathrm{~kW}$ flash lamps oriented at

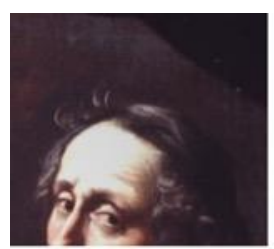

a)

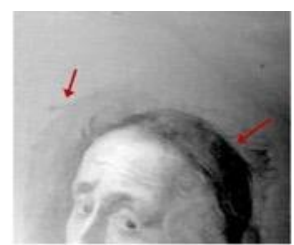

b)

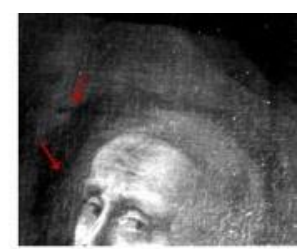

c)
Figure 4. The 'Ritratto di Mario Nuzzi che dipinge un vaso di fiori', Giovanni Maria Morandi and Mario Nuzzi, Chigi Palace, Ariccia. (a) Picture and corresponding (b) thermogram and (c) mid-infrared reflectogram in which the arrows indicate some variations in Nuzzi's hairstyle.

$45^{\circ}$ with respect to the surface of the investigated sample, delivering a few millisecond-long pulses. The emitted light from the lamps is filtered in order to eliminate the mid-infrared spectral component and, hence, to suppress any contributions to the recorded signal originating from reflections at the sample surface.

In the MIR technique, the sample illumination is performed using a continuous-wave halogen lamp positioned at about $2 \mathrm{~m}$ from the paintings. In both these techniques, the images are recorded by means of a Cedip JADE camera $(320 \times 240$ pixel, InSb focal plane array, $30 \mu \mathrm{m}$ pitch, 3.6-5.1 $\mu \mathrm{m}$ wavelength range, noise equivalent temperature difference $<25 \mathrm{mK}$ at $30^{\circ} \mathrm{C}$ ), positioned perpendicularly to the painting surface. Image acquisition and processing are conducted using Altair 5.50 software.

\section{RESULTS}

In the following discussion, the thermographic results will be compared with those obtained by mid-infrared reflectography in the areas of the paintings under investigation. To facilitate the comparison, the thermograms are presented with an inverted grey palette so that the hotter elements will appear darker in the images.

\subsection{Giovanni Maria Morandi and Mario Nuzzi's painting}

A series of pentimenti were detected in the 'Ritratto di Mario Nuzzi che dipinge un vaso di fiori' by Giovanni Maria Morandi and Mario Nuzzi. As an example, both the thermogram (Figure $4 \mathrm{~b})$ and the mid-infrared reflectogram (Figure 4c) reveal several changes to the initial concept of the painting. The arrows in the figures indicate a different hairstyle and head contouring with respect to the current appearance of the painting (Figure 4a).

A further element highlighted by the PT and MIR investigations is shown in Figure 5. The thermogram (Figure 5b) and the mid-infrared reflectogram (Figure $5 \mathrm{c}$ ) both detect the stitching line of the two separate pieces that form the canvas

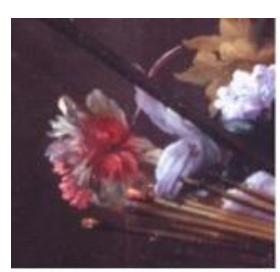

a)

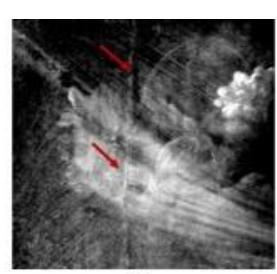

b)

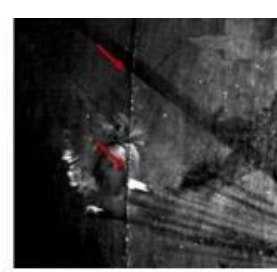

c)
Figure 5. The 'Ritratto di Mario Nuzzi che dipinge un vaso di fiori', Giovanni Maria Morandi and Mario Nuzzi, Chigi Palace, Ariccia. (a) Picture and corresponding (b) thermogram and (c) mid-infrared reflectogram in which the arrows indicate the join between the two pieces of canvas. 


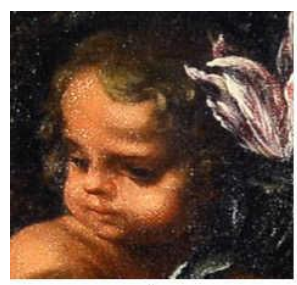

a)

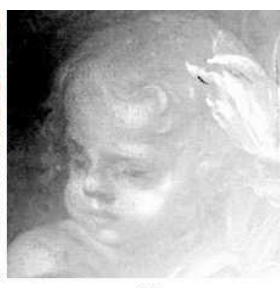

b)

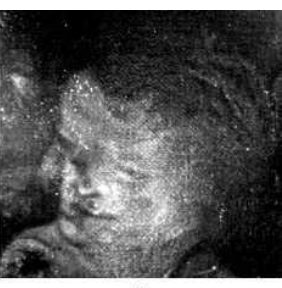

c)
Figure 6. The 'Primavera', Filippo Lauri and Mario Nuzzi, Chigi Palace, Ariccia (a) Picture of the cherub and (b) corresponding thermogram; (c) mid-infrared reflectogram in which the arrows indicate the pentimento.

(indicated by the arrows in the figures), which has been reported in the literature [23].

It is worth noting that the pentimenti has only been detected on Nuzzi's head, thus evidencing the great attention shown by Giovanni Maria Morandi to the realistic representation of Nuzzi's physiognomy. With the exception of the join between the two pieces of canvas, the thermographic results do not show any defects or inhomogeneities, thus indicating the painting's good state of conservation.

\subsection{Filippo Lauri and Mario Nuzzi's painting}

In the 'Primavera' by Filippo Lauri and Mario Nuzzi, several pentimenti were revealed, especially among the numerous cherubs. For instance, the mid-infrared reflectogram (Figure 6c) shows several changes to the initial concept of the cherub's physiognomic traits (indicated by the arrows), which are not visible in the thermogram (Figure 6b), thus indicating a pentimento beneath the surface pictorial layer.

Important information has also been obtained by recovering the contrast of some of the darkened features, such as those concerning the cherub displayed in Figure 7.

In this case, PT allowed the recovery of the cherub's physiognomic traits and the contouring of his entire head (arrow in Figure 7b), while MIR revealed some variations near the eyes, nose and mouth (dashed arrows in Figure 7c).

Furthermore, interesting features came to light from the analysis of the flowers (Figure 8). Unlike the MIR images, which do not show any relevant features, probably because of the presence of the highly reflective varnish layer (Figure 8b), PT enabled the detection of several elements. In fact, the thermogram recorded just after the light pulse allowed the recovery of floral details (arrows in Figure 8c) that are not clearly visible to the naked eye, while the PT image recorded at increasing delay times detected the canvas pattern (Figure 8d).

Moreover, several canvas defects were revealed by PT and MIR in the area of the woman's hand (Figure 9). Both the thermogram (Figure 9b) and the reflectogram (Figure 9c) highlight the presence of repaired lacunas, as indicated by the arrows in the figures.

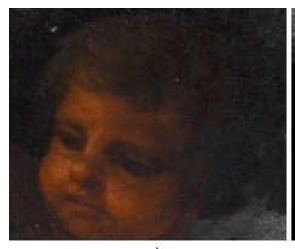

a)

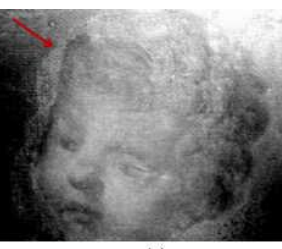

b)

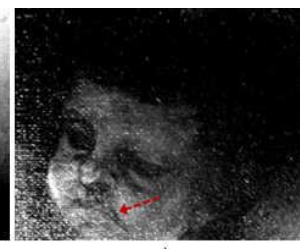

c)
Figure 7. The 'Primavera', Filippo Lauri and Mario Nuzzi, Chigi Palace, Ariccia (a) Picture of the cherub and corresponding (b) thermogram and (c) midinfrared reflectogram in which the arrows indicate the head contouring and some variations in the cherub's nose and mouth.

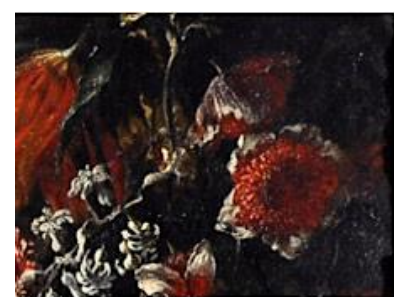

a)

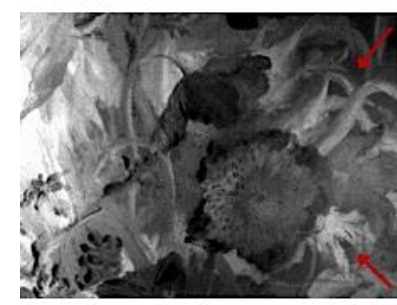

c)

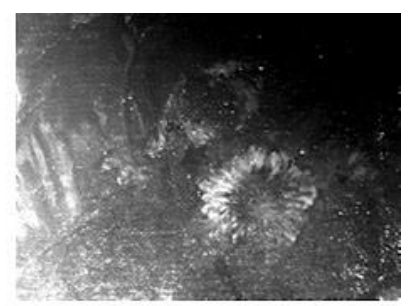

b)

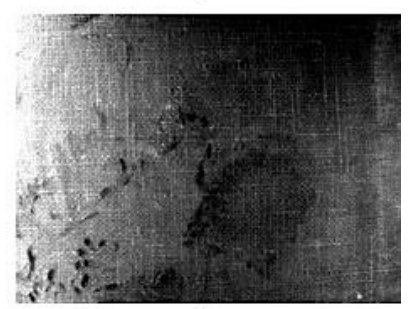

d)
Figure 8. The 'Primavera', Filippo Lauri and Mario Nuzzi, Chigi Palace, Ariccia. (a) Picture of flowers and corresponding (b) mid-infrared reflectogram and thermograms recorded just after the light pulse (c) and at increasing delay times (d).

The IR investigations of the 'Primavera' painting allowed the detection of several changes to the initial painting concept. Such changes mainly concern the representation of human figures, such as in the case of the cherubs. On the contrary, the floral elements seem to have been depicted by the artist with more confidence, as evidenced by the absence of clear pentimenti, and are actually covered in part by the dark tones of the painting. Finally, unlike the results obtained in the portrait, here, the thermographic investigations enabled the detection of structural features, such as the repaired lacunas, indicating the occurrence of previous restorations of the painting.

\subsection{Andrea Sacchi's painting}

Mid-infrared imaging investigations were carried out in order to characterise the 'Ebbrezza di Noe' by Andrea Sacchi. In this painting, several pentimenti were revealed, such as the one reported in Figure 10. In this case, the back of the figure shows numerous modifications, which can be observed both in the thermogram (Figure 10b) and in the mid-infrared reflectogram (Figure 10c). In both the images, the arrows indicate the sketch of a facial profile larger than the one that is visible (Figure 10a). Even in this case, some restored lacunas have been detected by PT (dashed circles in Figure 10b).

Another pentimento was observed on Noah's foot (Figure 11), as shown in the thermogram (Figure 11b) and in the mid-infrared

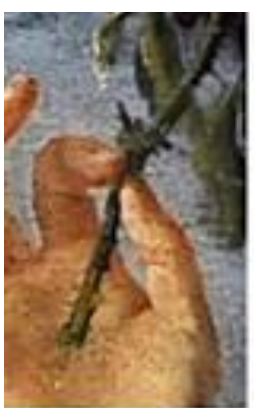

a)

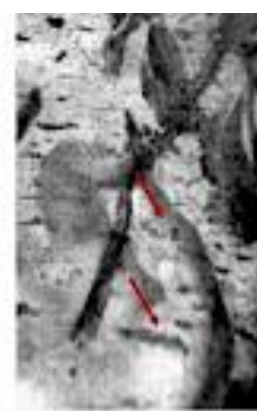

b)

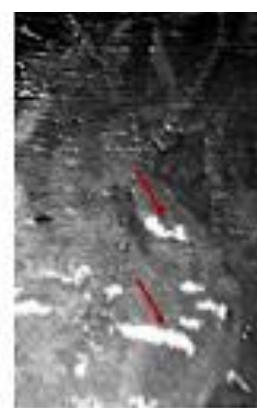

c)
Figure 9. The 'Primavera', Filippo Lauri and Mario Nuzzi, Chigi Palace, Ariccia. (a) Picture of the woman's hand and corresponding (b) thermogram and (c) mid-infrared reflectogram in which the arrows indicate the restored lacunas. 


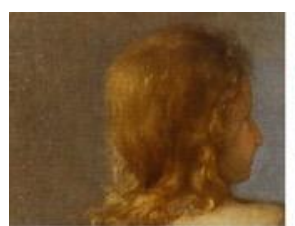

a)

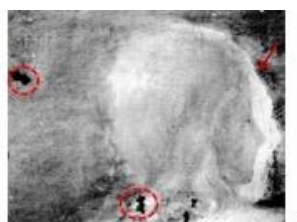

b)

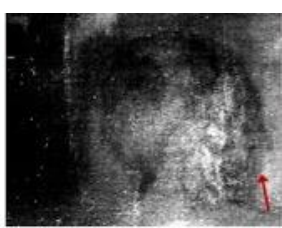

c)

Figure 10. The 'Ebbrezza di Noè' by Andrea Sacchi, Chigi Palace, Ariccia. (a) Picture of the figure from the back and corresponding (b) thermogram and (c) mid-infrared reflectogram, with arrows and circles indicating some changes in the facial profile and the restored lacunas, respectively.

reflectogram (Figure 11c). Moreover, as in the other investigated paintings, the thermogram enabled a series of complementary pieces of information to be obtained, such as the presence of defects in the canvas support. In this case, the thermogram shows a series of dark areas (the most significant is indicated by the dashed arrow in Figure 11b), probably corresponding to restored gaps or filled detachments, which, conversely, are barely visible in the reflectogram (Figure 11c).

Important information enabling an understanding of the artistic technique followed for the execution of this painting was obtained from the analysis of the images recorded in the area of Noah's face (Figure 12a). Here, the thermogram reveals several dark spots (arrows in Figure 12b), presumably corresponding to restorations of the painting's surface. Moreover, the lack of subsurface graphical features in the reflectogram corresponding to the hair and beard (arrow and circle in Figure 12c) could suggest the absence of underdrawings in this area.

The imaging investigation carried out on the painting by Andrea Sacchi reveals some pentimenti and small variations in the pictorial composition. Such findings can be thought to be in agreement with the continuous improvements introduced by Sacchi in the representation of this biblical story, but these variations do not indicate whether the Chigi painting is one of original versions of the numerous copies produced by the artist.

\section{CONCLUSIONS}

In this work, an innovative approach based on the combined use of two mid-wave infrared imaging techniques is proposed. The results obtained in the study of three XVII century paintings on canvas, preserved at the Chigi Palace in Ariccia, are presented. In particular, it has been shown how pulsed thermography and mid-infrared reflectography can be successfully used to investigate features lying beneath the surface pictorial layer and, consequently, to obtain complementary information about the stratigraphy of a painted artwork.

The capability of these techniques for investigating the paintings over different depth ranges has allowed the identification of several pentimenti in all three paintings, such as the head in the portrait by Mario Nuzzi, the cherubs of 'La

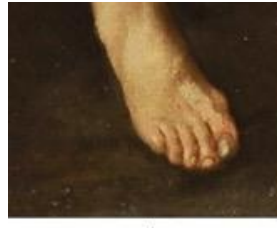

a)

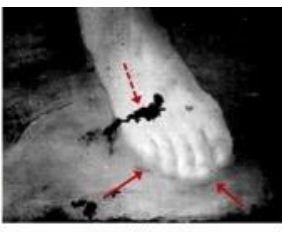

b)

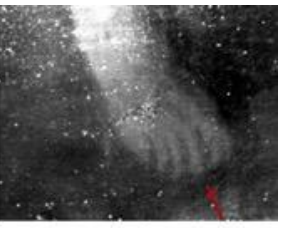

c)

Figure 11. The 'Ebbrezza di Noè' by Andrea Sacchi, Chigi Palace, Ariccia. (a) Picture of Noah's foot and corresponding (b) thermogram and (c) midinfrared reflectogram. The red arrows indicate some changes in position, and the dashed arrow in (b) indicates one of the restored gaps.

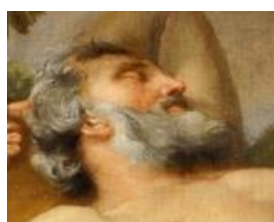

a)

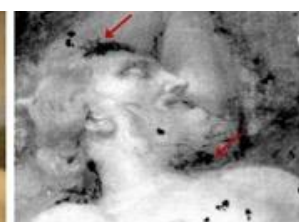

b)

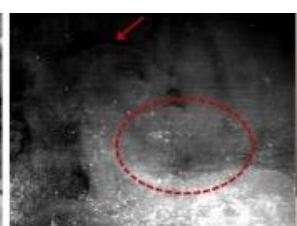

c)
Figure 12. The 'Ebbrezza di Noè' by Andrea Sacchi, Chigi Palace, Ariccia. (a) Picture of Noah's face and corresponding (b) thermogram in which the arrows indicate restoration, and (c) mid-infrared reflectogram, in which the arrow and the circle indicate the absence of graphical elements of the beard and hair.

Primavera' and the head of the man in the 'Ebbrezza di Noè'. Furthermore, thermography has enabled the characterisation of the canvas structure and, in particular, revealed the presence of repaired defects. In the case of the portrait by Mario Nuzzi, both techniques revealed the join between the two pieces of canvas. In 'La Primavera', the thermography investigations have highlighted the presence of numerous lacunas in relation to the woman's hand, presumably repaired in the last restoration. Similar surface damage has been revealed by thermography in 'Ebbrezza di Noè' near the area of Noah's foot and face. In the latter, the combination of the two mid-infrared imaging techniques has allowed significant information to be gathered for a better understanding of the process involved in the realisation of the hair and beard. In fact, these two elements are clearly visible in the thermographic image while, on the contrary, they are barely visible in the corresponding reflectogram, probably because of the transparency of the pigment in the mid-infrared range. This is consistent with the hypothesis that the absence of underdrawings in relation to Noah's beard and hair may suggest that these elements were painted by the artist in the final stage. These results could indicate that the painting preserved at the Chigi Palace in Ariccia is the original version of the numerous copies realised by the painter, Andrea Sacchi.

In conclusion, the results obtained by the combined use of thermography and reflectography have proven to offer useful information allowing an evaluation of the paintings' state of conservation and, in addition, new insights into the processes followed by the artists in the execution of such complex artworks.

\section{ACKNOWLEDGEMENT}

This study has been carried out within the framework of the ADAMO project, part of the activities of the Centre of Excellence of the District of Technologies for Culture of Lazio Region (DTC). The authors acknowledge the staff of Palazzo Chigi for their support during the analyses.

\section{REFERENCES}

[1] D. Gavrilov, R. G. Maev, D. P. Almond, A review of imaging methods in analysis of works of art: thermographic imaging method in art analysis, Can. J. Phys. 92 (2014), pp. 341-364. DOI: $10.1139 / \mathrm{cjp}-2013-0128$

[2] M. Faries, Analytical capabilities of infrared reflectography: an art historian's perspective, in: Scientific Examination of Art, Modern Techniques in Conservation and Analysis, The National Academies Press, Washington D.C., 2003, pp. 87-104. DOI: $10.1364 /$ AO.7.001711

[3] J. R. J. van Asperen de Boer, Infrared reflectography: a method for the examination of paintings, Appl. Opt. 7 (1968), p. 1711-1714. DOI: $\underline{10.1364 / A O .7 .001711}$ 
[4] C. M. Falco, High-resolution infrared imaging, Nat. Light Light Nat. III 7782 (2010), p. 778206. DOI: $10.1117 / 12.863575$

[5] A. C. Felici, G. Fronterotta, M. Piacentini, C. Nicolais, S. Sciuti, M. Vendittelli, C. Vazio, The wall paintings in the former refectory of the Trinità dei Monti convent in Rome: relating observations from restoration and archaeometric analyses to Andrea Pozzo's own treatise on the art of mural painting, J. Cult. Herit. 5 (2004), pp. 17-25.

DOI: $10.1016 /$ i.culher.2003.07.001

[6] J. R. J. van Asperen de Boer, Reflectography of paintings using an infrared vidicon television, Stud. Conserv. 14 (1969), pp. 96-118. DOI: $\underline{10.2307 / 1505392}$

[7] S. Ceccarelli, M. Guarneri, M. Ferri de Collibus, M. Francucci, M. Ciaffi, A. Danielis, Laser scanners for high-quality 3D and IR imaging in cultural heritage monitoring and documentation, J. Imaging 2018 4(11):130. DOI: $10.3390 /$ jimaging 4110130

[8] M. Hain, J. Bartl, V. Jacko, Multispectral analysis of cultural heritage artefacts, Meas. Sci. Rev. 3 (2003), pp. 9-12.

[9] C. Bonifazzi, P. Carcagnì, R. Fontana, M. Greco, M. Mastroianni, M. Materazzi, E. Pampaloni, L. Pezzati, D. Bencini, A scanning device for VIS-NIR multispectral imaging of paintings, J. Opt. A Pure Appl. Opt. 10 (2008). DOI: $10.1088 / 1464-4258 / 10 / 6 / 064011$

[10] M. Gargano, N. Ludwig, G. Poldi, A new methodology for comparing IR reflectographic systems, Infrared Phys. Technol. 49 (2007), pp. 249-253.

DOI: $10.1016 /$ i.infrared.2006.06.013

[11] D. Saunders, N. Atkinson, J. Cupitt, H. Liang, C. Sawyers, R. Bingham, SIRIS: a high resolution scanning infrared camera for examining paintings, Opt. Methods Arts Archaeol. 5857 (2005), p. 58570Q. DOI: $\underline{10.1117 / 12.612086}$

[12] C. Bonifazzi, P. Carcagnì, R. Fontana, M. Greco, M. Mastroianni, M. Materazzi, E. Pampaloni, L. Pezzati, D. Bencini, IR reflectography and active thermography on artworks: the added value of the 1.5-3 $\mu \mathrm{m}$ band, Appl. Sci. 8 (2018), p. 50. DOI: $10.3390 /$ app 8010050

[13] D. Ambrosini, C. Daffara, R. Di Biase, D. Paoletti, L. Pezzati, R. Bellucci, F. Bettini, Integrated reflectography and thermography for wooden paintings diagnostics, J. Cult. Herit. 11 (2010), pp. 196-204.

DOI: $10.1016 /$ i.culher.2009.05.001

[14] F. Mercuri, P. Buonora, C. Cicero, P. Helas, F. Manzari, M. Marinelli, S. Paoloni, A. Pasqualucci, F. Pinzari, M. Romani, A. Terrei, O. Verdi, G. Verona Rinati, U. Zammit, N. Orazi, Metastructure of illuminations by infrared thermography, J. Cult. Herit. 31 (2018), pp. 53-62.

DOI: $10.1016 /$ i.culher.2017.10.008

[15] G. Doni, N. Orazi, F. Mercuri, C. Cicero, U. Zammit, S. Paoloni, M. Marinelli, Thermographic study of the illuminations of a 15th century antiphonary, J. Cult. Herit. 15 (2014), pp. 692-697. DOI: $10.1016 /$ i.culher.2013.12.001

[16] F. Mercuri, S. Paoloni, N. Orazi, C. Cicero, U. Zammit, Pulsed infrared thermography applied to quantitative characterization of the structure and the casting faults of the Capitoline She Wolf, Appl. Phys. A Mater. Sci. Process. 123 (2017), pp. 1-8. DOI: $10.1007 / \mathrm{s} 00339-017-0958-6$

[17] S. Sfarra, M. Regi, M. Tortora, C. Casieri, S. Perilli, D. Paoletti, A multi-technique nondestructive approach for characterizing the state of conservation of ancient bookbindings, J. Therm. Anal. Calorim. 132 (2018), pp. 1367-1387. DOI: $\underline{10.1007 / \mathrm{s} 10973-018-6997-1}$

[18] F. Mercuri, S. Paoloni, C. Cicero, U. Zammit, N. Orazi, Infrared emission contrast for the visualization of subsurface graphical features in artworks, Infrared Phys. Techn. 89 (2018), pp. 223-230. DOI: $10.1016 /$ i.infrared.2018.01.012

[19] ADAMO project, 2018. Online. [Accessed 29 October 2020] http://progettoadamo.enea.it/
[20] F. Petrucci, Castelli e castellani. Viaggio attraverso le dimore storiche della provincia di Roma, De Luca Editori d'Arte, 2002, ISBN-13 : 978-8880165095.

[21] F. Petrucci, Sull'attività ritrattistica di Giovanni M. Morandi, Labyrinthos 33/34 (1998), pp.131-174.

[22] V. Golzio, Documenti artistici sul Seicento nell'archivio Chigi. Fratelli Palombi ed., Roma, 1939.

[23] F. Petrucci, Pittura di Ritratto a Roma. Il Seicento, vol. 3, Andreina \& Valneo Budai Editori, pp. 828, Roma, II, 2008. ASIN: B00H2HI984.

[24] G. Bocchi, U. Bocchi, Pittori di natura morta a Roma. Artisti italiani 1630-1750, 2005, EAN: 2560827351016.

[25] A. Angelini, Il cardinale Flavio Chigi committente e collezionista. Un breve profilo, in: Il Palazzo Chigi Zondadari a San Quirico d'Orcia. Architettura e Decorazione di un Palazzo Barocco. M. Eichberg, F. Rotundo (editors). San Quirico d'Orcia, 2009, p. 55.

[26] F. Petrucci, Mario Nuzzi, detto Mario de' Fiori / La Primavera, L'Estate, L'Autunno, L'Inverno, in: Fiori. Natura e Simbolo dal Seicento a Van Gogh, D. Benati, F. Mazzocca, A. Morandotti (editors). Forlì, 2010, pp. 136-145. ISBN-10: 8836615813.

[27] V. Golzio, Mario de' Fiori e la natura morta, L’Urbe (1965), p. 3.

[28] L. Laureati, Mario dei Fiori, in: The Dictionary of Art. London, 1996, p. 431, ISBN: 9781884446009.

[29] G. P. Bellori, Vita di Andrea Sacchi, in: Le vite de' Pittori, Scultori e Architetti Moderni. E. Borea (editor). 1976, pp. 535-568, ISBN 9788806200237.

[30] F. Petrucci, Tesori nascosti. Tino da Camaiano, Caravaggio, Gemito. Napoli, 2016, EAN: 9788891824004.

[31] L. Arcangeli, Andrea Sacchi, Ebbrezza di Noè, in: Quaderni del Barocco - Dipinti inediti del Barocco Italiano, vol. 11, Ariccia, 2010.

[32] F. Mercuri, N. Orazi, S. Paoloni, C. Cicero, U. Zammit, Pulsed thermography applied to the study of cultural heritage, Appl. Sci. 7 (2017), p. 1010.

DOI: $10.3390 /$ app 7101010

[33] N. Orazi, F. Mercuri, U. Zammit, S. Paoloni, M. Marinelli, A. Giuffredi, C. S. Salerno, Thermographic analysis of bronze sculptures, Stud. Conserv. 61 (2016), pp. 236-244. DOI: $10.1179 / 2047058415 Y .0000000025$

[34] F. Mercuri, N. Orazi, U. Zammit, A. Giuffredi, C. S. Salerno, C. Cicero, S. Paoloni, The manufacturing process of the Capitoline She Wolf: a thermographic method for the investigation of repairs and casting faults, J. Archaeol. Sci. Reports 14 (2017), pp. 199-207. DOI: $10.1016 /$ i.jasrep.2017.05.051

[35] M. Pucci, C. Cicero, N. Orazi, F. Mercuri, U. Zammit, S. Paoloni, M. Marinelli, Active infrared thermography applied to the study of a painting on paper representing the Chigi's family tree, Stud. Conserv. 60 (2015), pp. 88-96. DOI: 2047058413 Y.0000000117

[36] S. Paoloni, F. Mercuri, U. Zammit, Simultaneous specific heat, thermal conductivity and imaging evaluations in thin samples of 8CB liquid crystal dispersed with microemulsion of DDAB/water micelles, J. Chem. Phys. 145 (2016), pp.1-8. DOI: $10.1063 / 1.4963342$

[37] F. Mercuri, S. Paoloni, M. Marinelli, R. Pizzoferrato, U. Zammit, Study of the smecticA-hexaticB phase transition in homeotropic single domain samples of $65 \mathrm{OBC}$ liquid crystal by photopyroelectric calorimetry, J. Chem. Phys. 138 (2013), pp.1-4. DOI: $10.1063 / 1.4791707$

[38] C. Daffara, S. Parisotto, D. Ambrosini, Multipurpose, dual-mode imaging in the 3-5 $\mu \mathrm{m}$ range (MWIR) for artwork diagnostics: a systematic approach, Opt. Lasers Eng. 104 (2018), pp. 266-273. DOI: $10.1016 /$ i.optlaseng.2017.10.006

[39] Nondestructive Testing, Wiley, New York, 2001, ISBN: 978-0471-18190-3.

[40] J. R. J. van Asperen de Boer, Infrared Reflectograms of Panel Paintings, Stud. Conserv. 11 (1966), pp. 45-46. 